\title{
PATELLOFEMORAL RELATIONSHIPS IN RECURRENT PATELLAR DISLOCATION
}

\author{
U. M. KUJALA, K. ÖSTERMAN, M. KORMANO, O. NELIMARKKA, M. HURME, S. TAIMELA
}

\author{
From the University of Turku, Finland
}

\begin{abstract}
Magnetic resonance imaging was used to analyse the patellofemoral relationships during the first $30^{\circ}$ of knee flexion in women with recurrent patellar dislocation. The patellofemoral joints were imaged both sagittally and axially with the knee flexed $0^{\circ}, 10^{\circ}, 20^{\circ}$, and $30^{\circ}$. At the beginning of knee flexion the sulcus angle was greater than in unafiected women, the lateral patellofemoral angle was smaller, the patella displaced further laterally, tilted more laterally and the congruence angle was directed more laterally. At $30^{\circ}$ of knee flexion these differences were less marked than at $0^{\circ}$ to $10^{\circ}$.

Logistic regression analysis showed that the sulcus angle at $10^{\circ}$ of knee flexion was the most diagnostic feature, indicating that there is an anatomical predisposition to recurrent dislocation and that pathological patellar tracking starts from the beginning of flexion. Traditional sunrise radiographic films taken at $25^{\circ}$ to $30^{\circ}$ knee flexion clearly miss diagnostically important information.
\end{abstract}

Recurrent patellar dislocation is seen more often in females than in males (Rünow 1983), the difference probably being due to an anatomical predisposition (Kujala et al 1989). Patella alta, dysplastic femoral sulcus and other anatomical factors such as increased joint laxity or $Q$ angle, have been suggested as aetiological factors.

Axial radiographic evaluation of patellofemoral incongruence requires at least $25^{\circ}$ to $30^{\circ}$ of knee flexion. Computerised tomography has been used to evaluate patellofemoral relationships during the first $30^{\circ}$ of knee flexion (Delgado-Martins 1979; Martinez et al 1983; Sasaki and Yagi 1986; Schutzer, Ramsby and Fulkerson 1986a,b; Fulkerson et al 1987), and in an earlier study we analysed this same range of movement in normal

U. M. Kujala, MD, Specialist in Sports Medicine

S. Taimela, BM, Medical Student

Paavo Nurmi Centre, Sports Medical Research Unit, University of

Turku, Kiinamyllynkatu 10, SF-20520 Turku, Finland.

K. Österman, MD, Orthopaedic Surgeon

Orthopaedic Hospital of the Invalid Foundation, Tenholantie 10, SF00280 Helsinki.

M. Kormano, MD, Radiologist

O. Nelimarkka, MD, Orthopaedic Surgeon

Department of Diagnostic Radiology and Department of Surgery,

University Central Hospital, SF-20520 Turku.

M. Hurme, MD, Surgeon

Department of Surgery, City Hospital, Kunnallissairaalantie 20, SF20700 Turku.

Correspondence should be sent to Dr U. M. Kujala.

(C) 1989 British Editorial Society of Bone and Joint Surgery $0301-620 \mathrm{X} / 89 / 5171 \$ 2.00$

J Bone Joint Surg [Br] 1989; 71-B:788-92. patellofemoral joints using magnetic resonance imaging (MRI) (Kujala et al 1989). We showed that the patella normally lies in a lateral and tilted position in knee extension and undergoes medialisation during the first $30^{\circ}$ of flexion. The aim of this present study was to use MRI to compare the patellofemoral relationships of knees with recurrent patellar dislocation with those of normal knees during the first $30^{\circ}$ of knee flexion.

\section{PATIENTS AND METHODS}

The study group comprised 11 women aged 17 to 45 years, with recurrent patellar dislocation which had not been operated on; seven right knees and six left were involved. The diagnostic criterion for recurrence was two or more documented dislocations. None of the first dislocations was associated with direct high-energy trauma, and no patient had an associated relevant syndrome. One patient had had an earlier reconstructive operation for recurrent patellar dislocation on the contralateral side. Ten women aged 20 to 30 years volunteered to act as normal controls. They had no history or signs of abnormality; five right and five left knees were studied (Table I) (Kujala et al 1989). There was no difference in the physical activity habits of the two groups.

The MRI was performed on $0.02 \mathrm{~T}$ images Acutscan (Instrumentarium, Palomex division, Finland), using a special surface coil (Kujala et al 1989). The images were produced with the subject supine, the quadriceps relaxed and the knee flexed to $0^{\circ}, 10^{\circ}, 20^{\circ}$ and $30^{\circ}$. Special 
Table I. Age, height, and weight (mean \pm s.d.) of the patients and the controls

\begin{tabular}{lll}
\hline & $\begin{array}{l}\text { Dislocating } \\
\text { patellae } \\
\text { (13 knees) }\end{array}$ & $\begin{array}{l}\text { Controls } \\
\text { (10 knees) }\end{array}$ \\
\hline Age (years) & $26.7 \pm 6.0$ & $24.5 \pm 3.9$ \\
Height (cm) & $165.2 \pm 6.8$ & $165.4 \pm 5.5$ \\
Weight (kg) & $58.4 \pm 9.6$ & $55.6 \pm 6.5$ \\
\hline
\end{tabular}

Table II. Numerical values (mean \pm s.d.) of the indices measured from sagittal images with the knee in $30^{\circ}$ of knee flexion. Length of the patellar tendon (LT), length of the patella (LP), their proportion (LT/LP), patellar width (PW), distance between the most anterior points of the medial and lateral condyles (CW) (Fig. 2), distance between the line passing the posterior surface of the femoral condyles tangentially and the most anterior points of lateral ( $\mathrm{LCH}$ ) and medial $(\mathrm{MCH})$ condyles and the bottom of the sulcus ( $\mathrm{SH}$ ) (Fig. 2), femoral sulcus depth index (FSD, see text).

\begin{tabular}{lll}
\hline & $\begin{array}{l}\text { Dislocating } \\
\text { patellae } \\
(\mathrm{n}=13 \mathrm{knees})\end{array}$ & $\begin{array}{l}\text { Controls } \\
(\mathrm{n}=10 \mathrm{knees})\end{array}$ \\
\hline LT $(\mathrm{mm})$ & $51 \pm 5^{*}$ & $47 \pm 4$ \\
LP $(\mathrm{mm})$ & $40 \pm 5$ & $41 \pm 3$ \\
LT $/ \mathrm{LP}$ & $1.31 \pm 0.20^{*}$ & $1.15 \pm 0.08$ \\
$\mathrm{PW}(\mathrm{mm})$ & $37 \pm 2$ & $39 \pm 4$ \\
$\mathrm{CW}(\mathrm{mm})$ & $30 \pm 3^{*}$ & $33 \pm 3$ \\
LCH $(\mathrm{mm})$ & $53 \pm 7 \dagger$ & $60 \pm 3$ \\
$\mathrm{SH}(\mathrm{mm})$ & $50 \pm 7$ & $54 \pm 4$ \\
MCH $(\mathrm{mm})$ & $52 \pm 8 \dagger$ & $60 \pm 3$ \\
FSD & $5 \pm 4^{+}$ & $12 \pm 4$ \\
\hline
\end{tabular}

$* \mathrm{p}<0.05+\mathrm{p}<0.01 \mp \mathrm{p}<0.001$

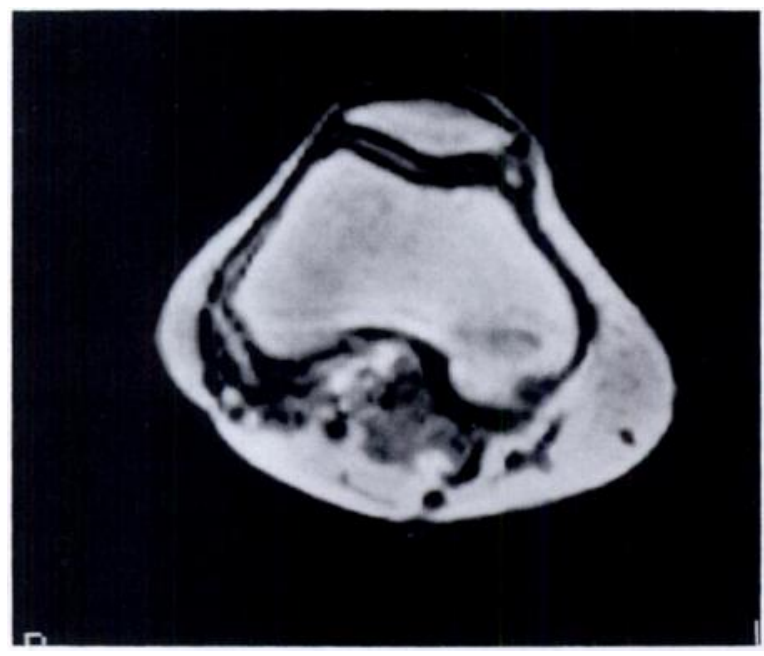

Fig. 1

Axial MR image at $30^{\circ}$ knee flexion of a woman with recurrent patellar dislocation. equipment was used to support the knee at the correct angle and to maintain the fore-foot vertical. At each knee position an axial image was used to focus the sagittal plane, followed by a midpatellar sagittal image and an axial image focused exactly through the middle of the patellar articular cartilage (Fig. 1).

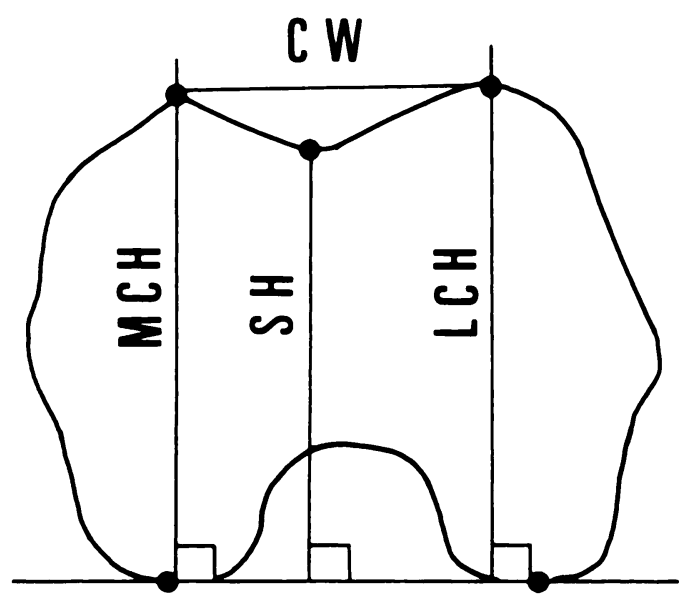

Fig. 2

The femoral parameters used in this study. Distance between the most anterior points of the medial and lateral condyles $(\mathrm{CW})$. Distance of the most anterior points of lateral (LCH) and medial (MCH) condyles and the bottom of the sulcus $(\mathrm{SH})$ from the line joining the posterior surface of the femoral condyles.

The following indices were measured from the MRIs using computer assistance (Figs 2 to 7):

\section{Sagittal images}

The height of the patella, using a modification of the Insall and Salvati (1971) method (LT/LP), relating the length of the patellar tendon (LT) to the length of the patella (LP).

\section{Axial images}

The patellar width (PW)

The distance between the most anterior points of the medial and lateral condyles $(\mathrm{CW})$

The femoral sulcus depth index (FSD), a line is drawn tangential to the posterior surface of the femoral condyles and the distances from this line to the most anterior points of the lateral $(\mathrm{LCH})$ and medial $(\mathrm{MCH})$ condyles and to the bottom of the sulcus (SH) are measured. FSD $=\mathrm{LCH}+\mathrm{MCH}-(2 \times \mathrm{SH})$

The sulcus angle (SA) (Brattström 1964)

The lateral patellofemoral angle (LPA) (Laurin, Dussault and Levesque 1979)

The lateral patellar displacement (LPD) (Laurin et al 1979)

The lateral patellar tilt (LPT), the angle between the line intersecting the widest part of the patella and the line tangential to the anterior surfaces of the femoral condyles The congruence angle (CA) (Merchant et al 1974). 
All the indices used for comparison between the groups were measured by the first author (UMK). To study interobserver variation, two different physicians measured the same series of images of 20 knees as a blind test. The mean and standard deviation of the interobserver differences (Bland and Altman 1986) were: $0.15 \pm$ $2.70 \mathrm{~mm}$ for LT (in $30^{\circ}$ of knee flexion), $0.35 \pm 1.42 \mathrm{~mm}$ for $L P, 0.90 \pm 2.32 \mathrm{~mm}$ for $\mathrm{PW}, 0.32 \pm 3.00 \mathrm{~mm}$ for $\mathrm{CW}$, $0.30 \pm 1.64 \mathrm{~mm}$ for $\mathrm{LCH}, 0.20 \pm 2.10$ for $\mathrm{SH}, 0.40 \pm 2.01$ for $\mathrm{MCH}, \leq 4.78 \pm 5.67^{\circ}$ (in different knee flexions) for $\mathrm{SA}, \leq 2.06 \pm 3.26^{\circ}$ for LPA, $\leq 2.29 \pm 2.82 \mathrm{~mm}$ for LPD, $\leq 2.56 \pm 3.91^{\circ}$ for $\mathrm{LPT}$, and $\leq 2.50 \pm 8.60^{\circ}$ for CA. Intraobserver variation was also studied and the variation was smaller or as small as the intra-observer variation for all the indices.

The statistical analysis was carried out using programs (ID, 2D, 3D, 6D, LR) of the BMDP statistical software. $T$-test or Mann-Whitney's $U$ test was used for comparison of the study group and the controls. Correlation coefficients between different measurements were calculated. The statistical analysis also included a multivariate analysis (logistic regression analysis).

\section{RESULTS}

In knees with recurrent patellar dislocation the patella lay higher than in the control knees $(\mathrm{p}<0.05)$, and, at $30^{\circ}$ knee flexion, the distance between the most anterior points of the medial and lateral condyles was shorter $(p<0.05)$, and the femoral sulcus depth index was smaller $(p<0.001)$ than in the control knees (Table II). The sulcus angle (Fig. 3), lateral patellofemoral angle (Fig. 4), lateral patellar displacement (Fig. 5), lateral patellar tilt (Fig. 6), and congruence angle (Fig. 7) differed significantly between the groups in the first stage of knee flexion, indicating that dislocating patellae were more lateralised and tilted. The difference between the groups decreased from extension to $30^{\circ}$ knee flexion (Figs 3 to 7).

Logistic regression analysis revealed that the factors which differed most between the groups were the sulcus angle measured at $10^{\circ}$ knee flexion, followed by the lateral patellofemoral angle measured at $0^{\circ}$. The sulcus angle was at least $170^{\circ}$ at $10^{\circ}$ knee flexion for all dislocating patellofemoral joints, but for only one knee in the control group. Five knees with dislocating patellae had a sulcus angle of more than $180^{\circ}$ at $10^{\circ}$ knee flexion. The congruence angle was negative (open medially) or zero in none of the dislocating knees and in six control knees at $10^{\circ}$ flexion and in 10 dislocating knees and in all control knees at $30^{\circ}$ flexion.

Increased patellar tilt and patellar lateralisation were usually seen in the same knees. The correlation coefficient between lateral patellar tilt and lateral patellar displacement for all subjects at all knee flexion angles was 0.68 ; that between the lateral patellofemoral angle and lateral patellar displacement was -0.62 . The

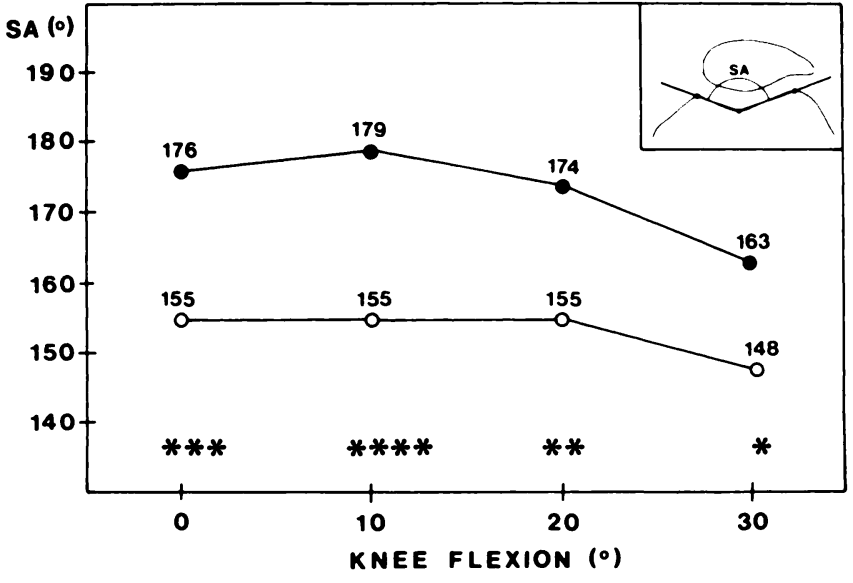

Fig. 3

The mean sulcus angle (SA) in knees with dislocating patellae $(O)$ and in control knees $(O)$ in different knee flexions. Asterisks indicate statistical difference between the groups $\left(* \mathrm{p}<0.05^{* *} \mathrm{p}<0.01 * * *\right.$ $\left.\mathrm{p}<0.001^{* * * *} \mathrm{p}<0.0001\right)$.

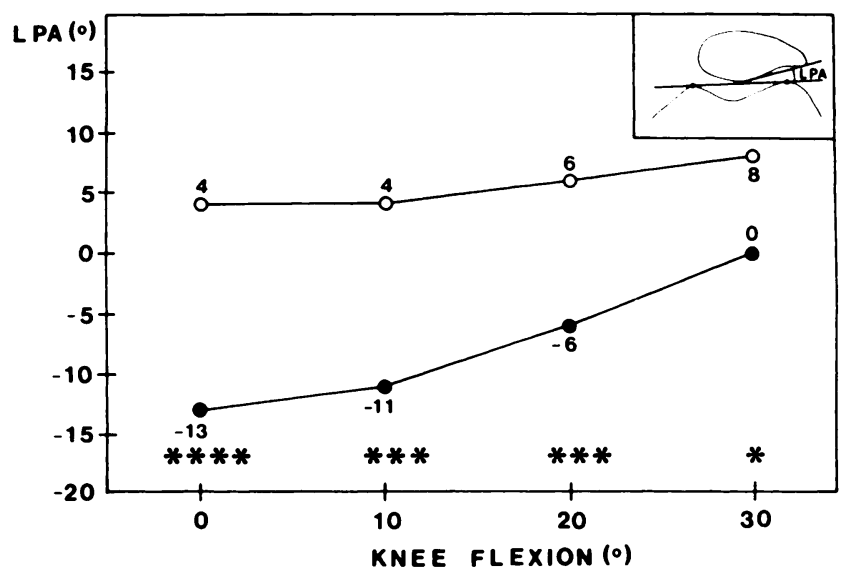

Fig. 4

The mean lateral patellofemoral angle (LPA) in knees with dislocating patellae $(O)$ and in control knees $(O)$ in different knee flexions. Asterisks indicate statistical difference between the groups $\left({ }^{*} p<0.05\right.$ $\left.{ }^{* *} p<0.01 * * * p<0.0011^{* * *} p<0.0001\right)$.

correlation coefficients for the patients at different knee flexions were 0.65 to 0.75 between the lateral patellar tilt and lateral patellar displacement and -0.58 to -0.79 between the lateral patellofemoral angle and lateral patellar displacement.

\section{DISCUSSION}

Measuring the patellofemoral indices by computed tomography or MRI and taking one specific section through the trochlea gives different results from those obtained by traditional sunrise radiographs. With MRI we produced an axial image through the centre of the patellar articular cartilage and we consider that this gives the most accurate information regarding condylar sup- 


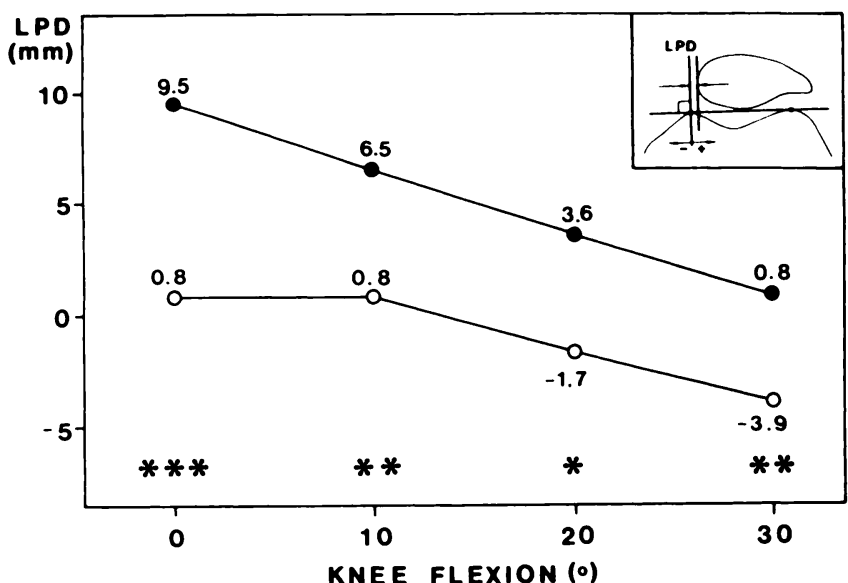

Fig. 5

The mean lateral patellar displacement (LPD) in knees with dislocating patellae $(O)$ and in control knees $(O)$ in different knee flexions. Asterisks indicate statistical difference between the groups $(* \mathrm{p}<0.05$ ${ }_{* *} p<0.01{ }^{* * *} p<0.001$ ).

port for the patella at different angles, even though cadaver experiments have shown that during the beginning of the knee flexion only the inferior part of the patellar cartilage is in contact with the trochlea (Goodfellow, Hungerford and Zindell 1976). Fulkerson et al (1987) have used the posterior femoral condyles for reference when measuring patellar tilt, but we measured the indices from axial images with reference to the anterior femoral condyles, since in cases of patella alta, the posterior femoral condyles may be low and, in our technique, changes significantly during knee flexion. Although the indices used in this study show the position of the patella with reference to the anterior femoral condyles, our analysis showed that the difference between the height of the lateral ( $\mathrm{LCH})$ and medial $(\mathrm{MCH})$ femoral condyles in axial images at different knee flexions

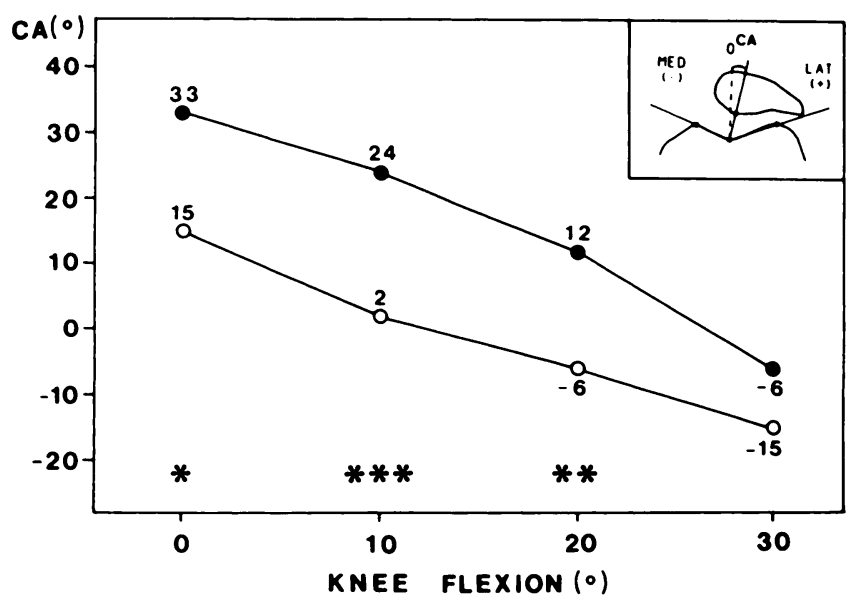

Fig. 7

The mean congruence angle (CA) in knees with dislocating patellae (O) and in control knees $(O)$ in different knee flexions. Asterisks indicate statistical difference between the groups $\left({ }^{*} p<0.05 * * p<0.01\right.$ $* * * p<0.001$ )

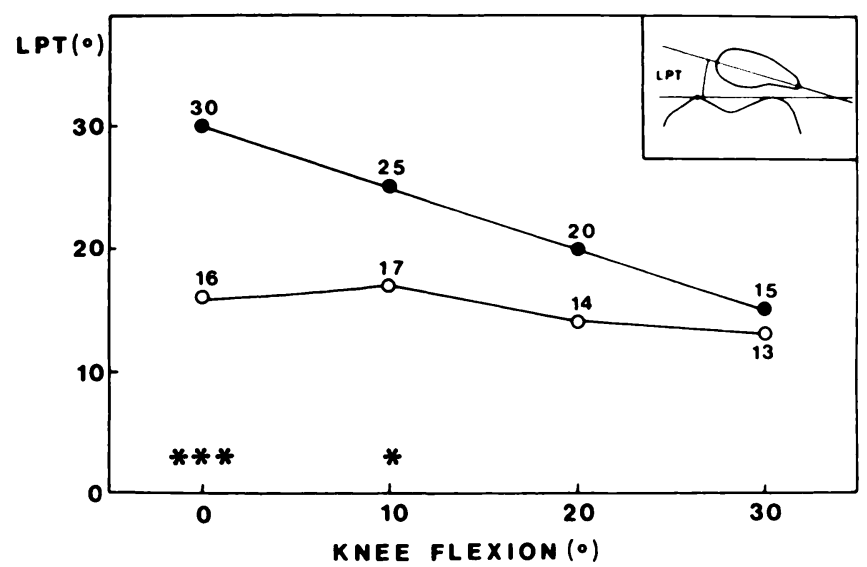

Fig. 6

The mean lateral patellar tilt (LPT) in knees with dislocating patellae $(O)$ and in control knees $(O)$ in different knee flexions. Asterisks indicate statistical difference between the groups $(* p<0.05 * * *$ $\mathrm{p}<0.001$ )

did not change significantly and was not the reason for the increased lateral tilt in knee extension.

In patients with patellar dislocation the patella lay higher (Insall, Goldberg and Salvati 1972), and the sulcus width was smaller than normal; these features, together with the low femoral sulcus depth index, decrease patellar stability. The lower lateral and medial condylar height in patients with dislocation may in part be explained by patella alta. It has also been found that there is a highly significant correlation between patella alta and a shallow trochlea (Hvid, Andersen and Schmidt 1983). The patella also lay more laterally in the femoral sulcus and the femoral condyles gave less support to the patella.

The sulcus angle at $10^{\circ}$ of knee flexion differentiated the groups most clearly on the basis of logistic regression analysis. There was only one value which overlapped between the groups. In $38 \%$ of the dislocating knees the sulcus angle was actually convex. If we define those patellofemoral joints as congruent where the $\mathrm{CA}$ is zero or opens medially, we can conclude that all control knees were congruent at $30^{\circ}$ knee flexion, but not at smaller flexion angles. Most of the dislocating patellofemoral joints $(77 \%)$ also were congruent at $30^{\circ}$ knee flexion, but the difference between the groups was greater during the beginning of flexion. Schutzer et al (1986a) categorised their patients with anterior knee pain into three groups: subluxation without tilt, subluxation with tilt, and tilt without subluxation. In our patients with patellar dislocation both increased tilt and increased lateralisation were seen consistently.

At the beginning of flexion the patella normally lies laterally in a somewhat tilted position; it moves to a congruent position during the first $30^{\circ}$ of knee flexion. In patients with recurrent dislocation, tilting and lateralisation are more obvious than in normal knees, the difference being most evident at the beginning of flexion. This finding explains the pathophysiology of recurrent 
dislocations and shows that an anatomical predisposition is significant in the aetiology.

MRI is a safe and useful method for individual evaluation of the patellofemoral relationships during the first $30^{\circ}$ of knee flexion and gives more diagnostic information than traditional sunrise films. It can also be used to evaluate whether re-alignment procedures have an effect on the position of the patella at the beginning of knee flexion.

The authors thank the Social Insurance Institution, Finland, and the Instrumentarium Scientific Fund for financial support of this study. The authors are very grateful to Dietrich Schlenzka, MD, for his valuable comments throughout the study. Our acknowledgements are also due to Leena Toivonen, RT, Olli Hautamäki, BA, Jussi Vatka, $\mathrm{BM}$, and Markku Komu, MSc, for their technical assistance.

No benefits in any form have been received or will be received from a commercial party related directly or indirectly to the subject of this article.

\section{REFERENCES}

Bland JM, Altman DG. Statistical methods for assessing agreement between two methods of clinical measurement. Lancet 1986; i: 307-10.

Brattström H. Shape of the intercondylar groove normally and in recurrent dislocation of patella: a clinical and x-ray-anatomical investigation. Acta Orthop Scand 1964; Suppl 68:1-148.

Delgado-Martins H. A study of the position of the patella using computerised tomography. J Bone Joint Surg [Br] 1979; 61-B: 443-4.
Fulkerson JP, Schutzer SF, Ramsby GR, Bernstein RA. Computerized tomography of the patellofemoral joint before and after lateral release or realignment. Arthroscopy 1987; 3:19-24.

Goodfellow J, Hungerford DS, Zindell M. Patello-femoral joint mechanics and pathology. I: Functional anatomy of the patellofemoral joint. J Bone Joint Surg [Br] 1976; 58-B:287-90.

Hvid I, Andersen LI, Schmidt H. Patellar height and femoral trochlear development. Acta Orthop Scand 1983; 54:91-3.

Insall J, Goldberg V, Salvati E. Recurrent dislocation and the highriding patella. Clin Orthop 1972;88:67-9.

Insall J, Salvati E. Patella position in the normal knee joint. Radiology $1971 ; 101: 101-4$.

Kujala UM, Österman K, Kormano M, Komu M, Schlenzka D. Patellar motion analyzed by magnetic resonance imaging. Acta Orthop Scand 1989; 60:13-6.

Laurin CA, Dussault R, Levesque HP. The tangential $x$-ray investigation of the patellofemoral joint: $x$-ray technique, diagnostic criteria and their interpretation. Clin Orthop 1979; 144:16-26.

Martinez S, Korobkin M, Fondren FB, Hedlund LW, Goldner JL. Computed tomography of the normal patellofemoral joint. Invest Radiol 1983; 18:249-53.

Merchant AC, Mercer RL, Jacobsen RH, Cool CR. Roentgenographic analysis of patellofemoral congruence. J Bone Joint Surg [Am] 1974; 56-A:1391-6.

Rünow A. The dislocating patella : etiology and prognosis in relation to generalized joint laxity and anatomy of the patellar articulation. Acta Orthop Scand 1983; 54:Suppl 201.

Sasaki T, Yagi T. Subluxation of the patella: investigation by computerized tomography. Int Orthop 1986; 10:115-20.

Schutzer SF, Ramsby GR, Fulkerson JP. Computed tomographic classification of patellofemoral pain patients. Orthop Clin North Am 1986; 17:235-48.

Schutzer F, Ramsby GR, Fulkerson JP. The evaluation of patellofemoral pain using computerized tomography: a preliminary study. Clin Orthop 1986; $204: 286-93$. 